\title{
Coal Miners Research Association
}

\section{Dale Newman}

University of Pittsburgh

The Coal Miners Research Association held its third annual conference December 12-13, 1980 in Columbus, Ohio. The program included presentations on "Health and Safety Legislation"; "Mining Fiction"; "The Labor Career of Dan McLaughlin: Miners" Leader from Illinois"; and "The Coming of the Huns to Southwestern Pennsylvania." Officers for 1981 are Tim Udegraff (Westmoreland County Community College), President; Roger Meade (The Ohio Historical Center), Treasurer; Dale Newman (University of Pittsburgh), Secretary: Ed Harley (UMWA), Council member.

The CMRA seeks to promote: cooperation among individuals and institutions engaged in the collection of oral history and archival materials which document the history and culture of coal mining in the United States; the initiation of new collecting efforts where needed; and the dissemination of information on collecting programs, ongoing research, publications, and other uses of these materials, including the sharing of these materials with the communities where they originated. Membership and participation in Association activities are welcomed. Address inquiries to: Treasurer, Roger Meade, CMRA; The Ohio Historical Center; I-71 and 17th Avenue; Columbus, Ohio 4.3211.

The Coal Miners Research Association publishes a newsletter. Tipple Talk, twice a year. Materials for publication should be submitted to: John Hevener, Editor Tipple Talk; Department of History: Ohio State University, Lima Campus; Lima, Ohio 45804.

The 1981 CMRA Annual Conference will be held in late July or August in Provo, Utah. Anyone who would like to be on the program, or obtain additional information about the Conference, should write to:

Gordon C. Casper

Box 51, 1222 Harold B. Lee Library

Brigham Young University

Provo, Utah 84602 